\title{
PRODUÇÃO DE MUDAS DE TOMATEIRO POR ESTAQUIA: EFEITO DO SUBSTRATO E COMPRIMENTO DE ESTACAS
}

\author{
TOMATO SEEDLING PRODUCTION BY CUTTINGS \\ ROOTED IN DIFFERENT SUBSTRATES
}

\author{
Heder Braun ${ }^{1}$; Paulo Cezar Cavatte ${ }^{2}$; José Augusto Teixeira do Amaral ${ }^{3}$; \\ José Francisco Teixeira do Amaral ${ }^{3}$; Edvaldo Fialho dos Reis ${ }^{5}$
}

\section{RESUMO}

Objetivou-se avaliar a viabilidade da produção de mudas de tomateiro por estaquia em diferentes substratos. O experimento foi conduzido em casa-de-vegetação no Centro de Ciências Agrárias da UFES, em Alegre-ES. Para a produção de mudas do tomateiro comparouse os substratos: mistura de solo + areia lavada + esterco bovino, Plantmax ${ }^{\circledR}$ e areia lavada. Os substratos foram acondicionados em recipientes plásticos ( $8 \mathrm{~cm}$ de altura e $7 \mathrm{~cm}$ de diâmetro), com capacidade para $200 \mathrm{~mL}$. Brotações foram retiradas de diferentes posições de plantas matrizes. Assim, as estacas foram padronizadas em três alturas: 5,8 e $11 \mathrm{~cm}$. O experimento foi instalado em esquema fatorial 3 x 3 (substratos x estacas) com três repetições e 30 mudas por parcela, totalizando 810 mudas. Foram detectados efeitos significativos para a interação entre os tipos de substratos e alturas de estacas nas seguintes características: comprimento do sistema radicular, diâmetro médio das raízes, relação entre a massa seca da parte aérea e massa seca do sistema radicular, massa seca total e massa seca do sistema radicular. Estacas de $5 \mathrm{~cm}$ apresentaram menor relação PA/SR independente do tipo de substrato e maior proporção de massa seca alocada no sistema radicular (53,8\%). A propagação vegetativa do tomateiro é viável, contudo maiores estudos sobre substratos alternativos, condições de enraizamento e padrão do material vegetal utilizado devem ser realizados.

Palavras-chave: Clones, Lycopersicon esculentum, propagação vegetativa.

\section{ABSTRACT}

The use of cuttings to implement tomato crops has fundamental importance for farmers, mainly due to high cost of seeds. This study aimed at evaluating the viability of the tomato seedling production by cuttings rooted in different substrates. The experiment was carried out in greenhouse at the Centro de Ciências Agrárias- UFES, Alegre- ES. The experiment was arranged in a complete randomized design using a $3 \times 3$ factorial scheme (substrate and cutting height) with three replicates. The following seedling characteristics were evaluated: rooting percentage, increase in height of aerial part, total length of root system, mean diameter of root system, dry matter of aerial part, and dry matter of root system. The total length of root system was not affected by the height of cuttings obtained from seedlings, whereas the commercial substrate for the establishment of seedlings provided plants with longer root system. The vegetative propagation of tomato plants via lateral shoots showed to be an alternative for the commercial cropping, becoming viable particularly for small farmers, mainly due the high cost of seeds.

Key words: Clones, Lycopersicon esculentum, vegetative propagation.

\section{INTRODUÇÃO}

Com a modernização da agricultura e a segmentação do mercado, surgiu a especulação na atividade de produção de mudas (Luz et al., 2000). Esta atividade tem sido apontada como uma das etapas mais importantes do sistema produtivo dela depende o desempenho final das plantas no campo de produção, tanto do ponto de vista nutricional, quanto do tempo necessário e, consequentemente, do número de ciclos produtivos possíveis por ano (Carmello, 1995). Segundo Minami (1995), 60\%

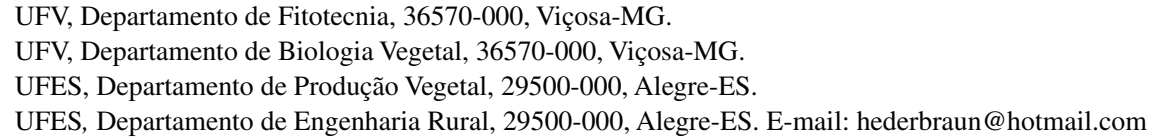


do sucesso de uma cultura residem no plantio de mudas de boa qualidade. O processo de produção é altamente dependente da utilização de insumos (Silveira et al., 2002). Neste contexto, o uso de sementes melhoradas, um dos insumos mais importante para o sucesso do empreendimento, porém com alto preço, podendo chegar a cem dólares por mil sementes, no caso do híbrido longa-vida (Fernandes et al., 2004), eleva o custo de produção. Ainda neste contexto, o substrato, tem se destacado em importância devido a sua ampla utilização.

O substrato hortícola pode ser conceituado como o meio onde se desenvolve as raízes das plantas produzidas em sementeiras e/ou viveiros de mudas olerícolas, ornamentais, frutíferas ou silvícolas (Carneiro, 1995). Esse deve garantir por meio de sua fase sólida a manutenção mecânica do sistema radicular e estabilidade da planta; da fase líquida o suprimento de água e nutrientes e; da fase gasosa, o suprimento de oxigênio e o transporte de dióxido de carbono entre as raízes e o ar externo (Lamaire, 1995). Deve ainda estar isento de elementos minerais ou qualquer outra substância em concentração fitotóxica, assim como de fitopatógenos, pragas e plantas indesejáveis (Carneiro, 1995; Minami, 1995). Desta forma, a escolha do substrato é uma das decisões mais importantes para produtores de mudas, principalmente quando se sabe que as condições ideais de cultivo dependem das exigências da espécie cultivada (Silveira et al., 2002). Alguns substratos comerciais atendem os requisitos para a produção de mudas, porém possuem custo elevado. Uma medida adequada consiste em utilizar substratos produzidos com materiais que possam ser obtidos facilmente na região. Assim, tem-se preocupado em introduzir novas tecnologias de produção que supram à necessidade e ao mesmo tempo sejam acessíveis as condições econômicas dos produtores.

Como alternativa para diminuir o custo de produção, com a aquisição de sementes, uma técnica promissora é o uso de propagação assexuada. Este processo consiste na reprodução de indivíduos a partir de partes vegetativas das plantas, caracterizando-se principalmente por manter inalterada a constituição genética do clone durante sucessivas gerações. A propagação vegetativa é comum em muitas espécies comercialmente importantes, sendo a tecnologia de enraizamento de estacas o procedimento mais econômico na propagação em grande escala (Foster, 1993). O tipo de estaca é decisivo para muitas espé- cies, contudo, de forma geral, as estacas de varias espécies de plantas enraízam com facilidade em grande diversidade de meios, porém, em plantas que apresentam dificuldade de enraizamento, o meio pode influir muito, não só na porcentagem de enraizamento, como, também, na qualidade do sistema radicular que se forma (Paiva \& Gomes, 1995). De acordo com Cheng \& Chu (2004), o método de propagação vegetativa do tomateiro via enraizamento do ápice mostrou ser alternativa importante para o cultivo comercial diminuindo o custo de produção, no entanto, segundo Fernandes (2004), o método mais utilizado e difundido para produção de mudas de tomate é por meio de sementes, sendo o enraizamento de estacas pouco comum. Por isso, objetvou-se avaliar a viabilidade da produção de mudas de tomateiro por estaquia em diferentes substratos.

\section{MATERIAIS E MÉTODOS}

Este experimento foi conduzido em casa de vegetação, no Centro de Ciências Agrárias da Universidade Federal do Espírito Santo, localizado no Município de Alegre/ES, latitude $20^{\circ} 45^{\prime}$ Sul, longitude $41^{\circ} 28^{\prime}$ Oeste e altitude de $247 \mathrm{~m}$. Foi avaliada a produção de mudas por estaquia do tomateiro hibrido 'Alambra', em diferentes substratos.

Para a produção de mudas do tomateiro comparou-se os substratos: mistura de solo + areia lavada + esterco bovino (1:1:1, v/v/v), Plantmax ${ }^{\circledR}$ (mistura de matéria orgânica de origem vegetal e vermiculita expandida) e areia lavada. Com exceção do Plantmax ${ }^{\circledR}$, todos os materiais utilizados na confecção dos substratos foram passados em peneira com malha de $2 \mathrm{~mm}$. Os substratos foram acondicionados em recipientes plásticos $(8 \mathrm{~cm}$ de altura e $7 \mathrm{~cm}$ de diâmetro), com capacidade para $200 \mathrm{~mL}$, na parte inferior foi feito aberturas para permitir livre drenagem. Após o enchimento dos recipientes e acondicionamento em casa de vegetação, procedeu-se a irrigação até a capacidade de campo.

As brotações foram retiradas de diferentes posições de plantas matrizes (geração $\mathrm{F}_{1}$, produzidas por semente), com bom aspecto fitossanitário e nutricional, acondicionadas em caixa de isopor, de modo a evitar perda de água. Na preparação das estacas, primeiramente, após pré-seleção do material vegetal, foram retiradas todas as folhas do ramo, 
deixando somente as folhas apicais. Posteriormente as estacas foram padronizadas em três alturas: 5 , 8 e $11 \mathrm{~cm}$. A padronização foi feita através de um corte em bisel na porção basal de cada estaca.

Após o preparo das estacas, foi realizado no centro de cada recipiente um orifício de $2,5 \mathrm{~cm}$ de profundidade, para o plantio das estacas. O sistema de irrigação utilizado foi o de micro-aspersão, sendo o turno de rega variando de 30 a 120 minutos de acordo com a evapotranspiração. A umidade dos substratos de cultivo foi mantida de modo que não houvesse acúmulo de água na superfície do recipiente.

Os tratamentos foram distribuídos no esquema fatorial $3 \times 3$ (substratos $x$ estacas), em delineamento inteiramente casualizado, com três repetições e 30 mudas por parcela, totalizando 810 mudas. Aos 18 dias após o plantio das estacas foi analisada a porcentagem de enraizamento (ENR), determinada através da proporção de estacas viáveis. Para a avaliação da produção de mudas foram analisadas, aos 24 dias após o plantio, seguintes características agronômicas: comprimento total (CSR) e diâmetro médio do sistema radicular (DR), após serem lavadas e destacadas da parte aérea, as raízes foram dispostas em lâminas de vidro e em seguida digitalizadas. O comprimento e diâmetro do sistema radicular foi estimado através do programa QuantRoot do Departamento de Solos da Universidade Federal de Viçosa, que realiza medição direta das raízes nas imagens digitalizadas em escala real, em que o programa cria linhas de igual comprimento ao das raízes; massa seca da parte aérea (MSPA), do sistema radicular (MSSR) e total (MST=MSPA+MSSR), o material vegetal foi seco em estufa com circulação forçada de ar à temperatura de $70^{\circ} \mathrm{C}$, até peso constante; relação entre massa seca da parte aérea e do sistema radicular (PA/SR=MSPA/MSSR); razão de massa seca da parte aérea (RMSPA=MSPA/MST); razão de massa seca do sistema radicular (RMSSR=MSSR/MST); ( $\mathrm{SRAD}=\pi \times \mathrm{DR} \times \mathrm{CSR})$; razão do comprimento do sistema radicular $(\mathrm{RCSR}=\mathrm{CSR} / \mathrm{MST})$; comprimento específico de raiz (CER=CSR/MSSR); taxa de crescimento absoluto referente ao acúmulo de massa seca [TCAM=(MST-MSE)/24] em que MSE=massa seca das estacas, estimada através da secagem de 5 estacas de cada altura; superfície radicular; taxa de crescimento absoluto referente ao incremento na altura das mudas [TCAA $=(\mathrm{AF}-$ $\mathrm{AE}) / 24]$, em que $\mathrm{AF}=$ altura da parte aérea final e $\mathrm{AE}=$ altura inicial das estacas.
Os dados obtidos foram submetidos à análise de variância e, os fatores significativos analisados pelo teste de Tukey em nível de significância de $5 \%$ de probabilidade.

\section{RESULTADOS E DISCUSSÃO}

Considerou-se o valor de probabilidade igual a $5 \%(\mathrm{p}=0,05)$ como o liminar para concluir a significância da análise estatística. Assim, foram detectados efeitos significativos para a interação entre os tipos de substratos e alturas de estacas nas seguintes características: comprimento do sistema radicular (CSR), diâmetro médio das raízes (DR), relação entre a massa seca da parte aérea e massa seca do sistema radicular (PA/SR), massa seca total (MST) e massa seca do sistema radicular (MSSR) (Tabela 1). Com exceção dos parâmetros razão da massa seca da parte aérea (RMSPA) $(\mathrm{p}=0,101)$ e razão de massa seca do sistema radicular (RMSSR) ( $p=0,103)$, foi verificado diferença significativa entre os substratos para as demais características avaliadas (Tabela 1). A altura das estacas não influenciou significativamente os parâmetros: porcentagem de enraizamento (ENR), MSSR, taxa de crescimento absoluto referente ao acréscimo em altura (TCAA) e RMSPA (Tabela 1). Para todos os parâmetros avaliados, o coeficiente de variação (CV) apresentou valores consideravelmente baixos, aproximadamente $20 \%$, o que credencia os dados apresentados neste trabalho (Tabela 1).

A visualização dos primórdios radiculares ocorreu em média aos 6 dias após o plantio das estacas, sendo 4 dias para o substrato Plantmax ${ }^{\circledR}, 6$ dias para $\mathrm{S}+\mathrm{A}+\mathrm{E}$ e 8 dias para areia, independente da altura das estacas. Fernandes et al. (2004) avaliando o enraizamento de estaca de tomateiro da cultivar Carmem, em espuma fenólica $(5,0 \times 5,0 \times 3,8 \mathrm{~cm})$, visualizaram o aparecimento das raízes na parte externa dos blocos aos 10 dias após a transferência para enraizamento. Em solução nutritiva aerada relataram o aparecimento de pequenas raízes e calos na parte basal das estacas, ocorreu aos 4 dias após a transferência para o enraizamento (Fernandes et al., 2004). Com base nestes dados, admite-se que a condição para o enraizamento afeta o padrão de expressão do potencial organogênico das estacas. Sendo as condições de umidade e aeração fundamentais para que o material vegetal possa expressar eficientemente este potencial. 
Tabela 1

Resumo do teste $\mathbf{F}$ com seus respectivos valores de probabilidade (p) e coeficiente de variação (CV) da análise de variância para as variáveis: ENR - enraizamento (\%), CSR-comprimento do sistema radicular (m), DR- diâmetro médio das raízes ( $\mathrm{mm})$, TCAM - taxa de crescimento absoluto referente ao acúmulo de massa seca (mg dia-1), MSPA - massa seca da parte aérea (g), MSSR - massa seca do sistema radicular (g), PA/SR relação entre massa seca da parte aérea e do sistema radicular $\left(\mathrm{g} \mathrm{g}^{-1}\right)$, MST - massa seca total (g), TCAA taxa de crescimento absoluto referente ao acréscimo em altura $\left(\mathrm{mm} \mathrm{dia}{ }^{-1}\right)$, SRAD - superfície radicular $\left(\mathrm{cm}^{2}\right)$, RMSPA - razão de massa seca da parte aérea ( $\left.\mathrm{g} \mathrm{g}^{-1}\right)$, RMSSR - razão de massa seca do sistema radicular $\left(\mathrm{g} \mathrm{g}^{-1}\right)$, RCSR - razão do comprimento do sistema radicular $\left(\mathrm{m} \mathrm{g}^{-1}\right)$ e CER - comprimento específico de raiz (m kg $\left.\mathrm{g}^{-1}\right)$ de mudas do tomateiro provenientes de diferentes substratos e altura de estacas

\begin{tabular}{|l|c|c|c|c|}
\hline \multirow{2}{*}{ Parâmetros } & \multicolumn{4}{|c|}{ Fonte de Variação } \\
\cline { 2 - 5 } & Substrato & Estaca & Substrato x Estaca & CV $(\%)$ \\
\hline ENR & $26,21(\mathrm{p}<0,001)$ & $1,98(\mathrm{p}=0167)$ & $2,11(\mathrm{p}=0,122)$ & 25,14 \\
\hline CSR & $148,15(\mathrm{p}<0,001)$ & $10,96(\mathrm{p}<0,001)$ & $9,27(\mathrm{p}<0,001)$ & 12,79 \\
\hline DR & $380,56(\mathrm{p}<0,001)$ & $14,39(\mathrm{p}<0,001)$ & $7,77(\mathrm{p}<0,001)$ & 11,25 \\
\hline TCAM & $102,24(\mathrm{p}<0,001)$ & $34,89(\mathrm{p}<0,001)$ & $2,83(\mathrm{p}=0,055)$ & 21,54 \\
\hline MSPA & $102,28(\mathrm{p}<0,001)$ & $49,40(\mathrm{p}<0,001)$ & $2,82(\mathrm{p}=0,056)$ & 16,79 \\
\hline MSSR & $93,44(\mathrm{p}<0,001)$ & $2,11(\mathrm{p}=0,149)$ & $4,76(\mathrm{p}=0,008)$ & 22,68 \\
\hline PA/SR & $19,03(\mathrm{p}<0,001)$ & $62,47(\mathrm{p}<0,001)$ & $10,64(\mathrm{p}<0,001)$ & 17,53 \\
\hline MST & $56,15(\mathrm{p}<0,001)$ & $18,86(\mathrm{p}<0,001)$ & $1,61(\mathrm{p}=0,216)$ & 24,14 \\
\hline TCAA & $44,75(\mathrm{p}<0,001)$ & $0,06(\mathrm{p}>0,999)$ & $20,12(\mathrm{p}=0,120)$ & 24,62 \\
\hline RMSPA & $2,61(\mathrm{p}=0,101)$ & $2,39(\mathrm{p}=0,120)$ & $0,24(\mathrm{p}>0,999)$ & $2,24(\mathrm{p}=0,105)$ \\
\hline RMSSR & $2,59(\mathrm{p}=0,103)$ & $21,55(\mathrm{p}<0,001)$ & 7,14 \\
\hline
\end{tabular}

As estacas apresentaram, em média, $92 \%$ de enraizamento. Estudando ENR nos diferentes substratos, valores semelhantes ( $96 \%)$ foram encontrados para os substratos Plantmax ${ }^{\circledR}$ e $\mathrm{S}+\mathrm{A}+\mathrm{E}$, superior em aproximadamente $12 \%$ a areia $(83,9 \%)$ (Tabela 2$)$. Por ter menor capacidade de retenção de água e reduzida porosidade, a areia não foi um substrato adequado para o enraizamento de estacas para a espécie em estudo. Shmitz et al. (1999) avaliando as características físicas dos diversos substratos comentam que materiais como solo e areia possuem excessiva densidade e reduzida porosidade, sendo deficiente em aeração. Assim, a adição de material orgânico (esterco bovino) ao solo contribuiu para melhoria de suas características físicas melhorando as condições para formação de raízes. Os substratos que apresentaram maior enraizamento exibiram valores semelhantes ao encontrado por Fernandes et al. (2004), que relataram aproximadamente $98 \%$ de enraizamento de estacas de tomateiro cultivar Carmem, em espuma fenólica e Gûl et al. (1994) que estudaram o enraizamento de estacas de tomate tratadas com hormônio e enraizadas em perlita. Contudo, as estacas de tomateiro, o nível interno de hormônio e substâncias relacionadas ao enraizamento foi suficiente para permitir a propagação vegetativa dessa cultura sem aplicação de reguladores de crescimento. As estacas que não apresentaram formação de primórdios radiculares apodreceram sem formar raízes. Esse comportamento foi descrito por Hartman \& Kester (1990) que associaram esse fenômeno com altas concentrações de nitrogênio e baixas concentrações de carboidratos nas estacas de tomate.

A taxa de crescimento absoluto (TCA) referente ao acúmulo de massa seca (TCAM) foi maior no substrato Plantmax ${ }^{\circledR}$, superior em 58,9\% ao $\mathrm{S}+\mathrm{A}+\mathrm{E}$ e 306,6\% a areia (Tabela 2). Quando avaliamos a TCAA não se verifica diferenças significativas entre os substratos Plantmax ${ }^{\circledR}$ e $\mathrm{S}+\mathrm{A}+\mathrm{E}$ apresentando em média $4,05 \mathrm{~mm} / \mathrm{dia}$, superior em $258,4 \%$ ao substrato areia. $\mathrm{O}$ substrato horticula deve garantir o 
Tabela 2

Valores médios dos parâmetros: enraizamento (ENR), taxa de crescimento absoluto (TCA), massa seca da parte aérea (MSPA), massa seca total (MST), razão de massa seca da parte aérea (RMSPA) e razão de massa seca do sistema radicular (RMSSR) de mudas do tomateiro em diferentes substratos e altura de estacas

\begin{tabular}{|c|c|c|c|c|c|}
\hline \multicolumn{2}{|c|}{ Parâmetros } & \multicolumn{2}{|c|}{ Substrato } & \multicolumn{2}{|c|}{ Estaca } \\
\hline \multirow{3}{*}{\multicolumn{2}{|c|}{$\operatorname{ENR}(\%)$}} & $S+A+E$ & $96,9^{\mathrm{a}}$ & 5 & $94,3^{\mathrm{a}}$ \\
\hline & & Plantmax $®$ & $94,7^{\mathrm{a}}$ & 8 & $92,3^{\mathrm{a}}$ \\
\hline & & Areia & $83,9^{\mathrm{b}}$ & 11 & $89,1^{\mathrm{a}}$ \\
\hline \multirow{6}{*}{ TCA } & \multirow{3}{*}{$\left(\mathrm{mg} \mathrm{dia}{ }^{-1}\right)$} & $S+A+E$ & $20,50^{\mathrm{b}}$ & 5 & $13,13^{\mathrm{c}}$ \\
\hline & & Plantmax $®$ & $32,57^{\mathrm{a}}$ & 8 & $22,57^{b}$ \\
\hline & & Areia & $8,01^{\mathrm{c}}$ & 11 & $25,38^{\mathrm{a}}$ \\
\hline & \multirow{3}{*}{$\left(\mathrm{mm} \mathrm{dia}{ }^{-1}\right)$} & $S+A+E$ & $4,07^{\mathrm{a}}$ & 5 & $3,14^{\mathrm{a}}$ \\
\hline & & Plantmax $®$ & $4,02^{\mathrm{a}}$ & 8 & $3,03^{\mathrm{a}}$ \\
\hline & & Areia & $1,13^{\mathrm{b}}$ & 11 & $3,05^{\mathrm{a}}$ \\
\hline \multirow{3}{*}{\multicolumn{2}{|c|}{ MSPA (g) }} & $\mathrm{S}+\mathrm{A}+\mathrm{E}$ & $0,58^{\mathrm{b}}$ & 5 & $0,36^{\mathrm{c}}$ \\
\hline & & Plantmax ® & $0,83^{\mathrm{a}}$ & 8 & $0,62^{\mathrm{b}}$ \\
\hline & & Areia & $0,31^{\mathrm{c}}$ & 11 & $0,73^{\mathrm{a}}$ \\
\hline \multirow{3}{*}{\multicolumn{2}{|c|}{ MST (g) }} & $S+A+E$ & $0,62^{\mathrm{b}}$ & 5 & $0,41^{\mathrm{b}}$ \\
\hline & & Plantmax $®$ & $0,91^{\mathrm{a}}$ & 8 & $0,67^{\mathrm{a}}$ \\
\hline & & Areia & $0,32^{\mathrm{c}}$ & 11 & $0,78^{a}$ \\
\hline \multirow{3}{*}{\multicolumn{2}{|c|}{ RMSPA }} & $S+A+E$ & $0,92^{\mathrm{a}}$ & 5 & $0,90^{\mathrm{a}}$ \\
\hline & & Plantmax ® & $0,90^{\mathrm{a}}$ & 8 & $0,93^{\mathrm{a}}$ \\
\hline & & Areia & $0,94^{\mathrm{a}}$ & 11 & $0,94^{\mathrm{a}}$ \\
\hline \multirow{3}{*}{\multicolumn{2}{|c|}{ RMSSR }} & $S+A+E$ & $0,08^{\mathrm{b}}$ & 5 & $0,10^{\mathrm{a}}$ \\
\hline & & Plantmax $®$ & $0,10^{\mathrm{a}}$ & 8 & $0,07^{b}$ \\
\hline & & Areia & $0,06^{\mathrm{b}}$ & 11 & $0,06^{b}$ \\
\hline
\end{tabular}

Médias obtidas entre diferentes substratos e tamanho de estacas seguidas por diferente letra diferem estatisticamente entre si pelo teste de Tukey $(\mathrm{p} \leq 0,05)$.

desenvolvimento do sistema radicular e estabilidade da planta, para assim, proporcionar o suprimento de água e nutrientes necessários ao seu crescimento. Portanto, os maiores valores de TCA apresentados pelo Plantmax ${ }^{\circledR}$ pode ser reflexo de sua composição, por possuir uma maior proporção de matéria orgânica, portanto, mais rico em nutrientes, esse substrato pode propiciar condições mais favoráveis para a planta absorver água e produzir massa seca. Este comportamento pode ser confirmado, avaliando a MSPA e MST. Esses resultados estão de acordo com os resultados alcançados por Rizzo \& Braz (2002), os quais constataram que o uso de substrato comercial Plantmax ${ }^{\circledR}$ proporcionou um bom desenvolvimento das mudas de tomateiro formadas a partir de brotos laterais. As raízes também obtiveram um bom desenvolvimento em seu comprimento e consequientemente, maior massa seca quando utilizou-se substrato comercial. Resultados concordantes foram obtidos por Smiderle et al. (2001), confirmando que o substrato Plantmax ${ }^{\circledR}$ propiciou maior massa de matéria seca das plântulas e das raízes de alface, aos 21 e 40 dias após a semeadura. Contudo, Pragana (1998) em testes de bioensaio com diversas hortaliças verificou que de modo geral, a adição de pó de coco melhorou o desempenho daquele substrato.

A altura inicial de estaca não afetou a TCCA, porém, o acúmulo de massa seca diária, verificada pela TCAM, foi decrescendo com a redução da altura das estacas, apresentando as estacas de $11 \mathrm{~cm}$ valores 12,5 e 93,3\% superior a estacas de 8 e $5 \mathrm{~cm}$, respectivamente (Tabela 2). Comportamento semelhante foi observado para a MSPA (Tabela 2). Após o plantio, as estacas passam por um período de ausência de raízes e folhas, assim, o crescimento é governado pelas reservas metabólicas. Estacas com maiores alturas possuem conteúdo maior de carboidratos que poderá ser utilizados na manutenção de maior taxa de crescimento inicial das mudas, formando primeiramente raízes e novas folhas para iniciar o processo fotossintético, aumentando a fonte de carboidratos que poderá ser utilizada para a respiração de manutenção e de desenvolvimento das mudas. Fachinello et al. (1995) verificaram que a formação de raízes em estacas de videira possui correlação significativa com teor de amido, sendo a porcentagem de enraizamento de $63 \%$ nas estacas mais ricas $35 \%$ nas intermediárias e $7 \%$ naquelas com menor concentração.

A MST foi estatisticamente igual entre as estacas de 8 e $11 \mathrm{~cm}$, apresentando valores médios de $0,72 \mathrm{~g} \mathrm{e} 75,6 \%$ superior a areia $(0,41 \mathrm{~g})$ (Tabela 2$)$. A igualdade entre aquelas estacas é explicada pelo maior acúmulo de massa seca no sistema radicular nas estacas de $8 \mathrm{~cm}$. A RMSPA não apresentou diferenças significativas entre os tratamentos (Tabela 2). No geral, $92 \%$ da MST estava alocada na parte aérea. A RMSSR apresentou respostas significativas entre os diferentes substratos e altura de estacas (Tabela 2). 
No substrato Plantmax ${ }^{\circledR} 10 \%$ da MST foi alocada no sistema radicular, aproximadamente $42,9 \%$ superior a proporção de massa seca acumulada no sistema radicular de mudas crescidas nos substratos $\mathrm{S}+\mathrm{A}+\mathrm{E}$ e areia. Estacas com $5 \mathrm{~cm}$ de altura apresentaram em média maior proporção de massa seca alocada no sistema radicular $(53,8 \%)$.

A altura de estaca não influenciou estatisticamente os parâmetros CSR e DR. Para o substrato $\mathrm{S}+\mathrm{A}+\mathrm{E}$ com valores médios de 5,39 $\mathrm{m}$ e $0,042 \mathrm{~mm}$, respectivamente (Tabela 3). Estacas com $5 \mathrm{~cm}$ apresentaram menor CSR quando submetidas ao Plantmax ${ }^{\circledR}$. No geral, maior CSR foi observado nas estacas de $11 \mathrm{~cm}$ enraizadas no substrato Plantmax ${ }^{\circledR}$ $(12,66 \mathrm{~m})$. Estacas enraizadas na areia apresentaram maior DR. Registra-se que o fato da areia apresentar mudas com raízes mais grossas, presumivelmente, menor condutividade hidráulica radial reduziria a absorção de água por unidade de comprimento de raiz. Cumpre ressaltar que baixa condutividade hidráulica radial, normalmente é uma característica indesejável sob suprimento hídrico abundante, pode reduzir potenciais perdas de água da raiz para o solo, ao longo de ciclos de desidratação, esse fato confirmaria a baixa capacidade da areia de manter a umidade o que causava a murcha das mudas no período de maior evapotranspiração. Ademais, a maior relação PA/SR culminaria em baixa habilidade de controlar perda de água.

Estacas de $5 \mathrm{~cm}$ apresentaram menor relação PA/SR independente do tipo de substrato (Tabela 3). Assim, apresentaram melhor equilíbrio entre superfície transpirante associada a uma maior quantidade relativa de raízes para suprir as perdas transpiratórias, possuindo uma capacidade maior de absorção de água por volume de solo. Menor PA/SR deve concorrer para menores taxa de uso da água e melhor capacidade de tolerar condições adversas. Mudas confeccionadas no substrato Plantmax ${ }^{\circledR}$ com estacas de 5, 8 e $11 \mathrm{~cm}$, nas mesmas condições, aqui descritas, foram levadas para plantio em campo, o melhor equilíbrio morfológico poderia explicar a

\section{REFERÊNCIAS BIBLIOGRAFICAS}

CARMELLO, Q.A.C. 1995. Nutrição e adubação de mudas hortícolas. In: MINAMI, K. Produção de mudas de alta qualidade em horticultura. São Paulo: T.A. Queiroz, p. 33-37.

CARNEIRO, J.G.A. 1995. Produção e controle de qualidade de mudas vegetais. Curitiba: UFPR/FUPEF, 451 p.
Tabela 3

Valores médios dos parâmetros: comprimento do sistema radicular (CSR), diâmetro médio das raízes (DR), massa seca do sistema radicular (MSSR) e relação entre massa seca da parte aérea e do sistema radicular (PA/SR) de mudas do tomateiro provenientes de diferentes substratos e altura de estacas

\begin{tabular}{|c|c|c|c|c|}
\hline \multirow{2}{*}{ Parâmetros } & \multirow{2}{*}{ Estaca } & \multicolumn{3}{|c|}{ Substrato } \\
\hline & & $S+A+E$ & Plantmax ${ }^{\circledR}$ & Areia \\
\hline \multirow{3}{*}{ CSR (m) } & 5 & $6,04^{\mathrm{aB}}$ & $8,91^{\mathrm{bA}}$ & $2,15^{\mathrm{bC}}$ \\
\hline & 8 & $5,61^{\mathrm{aB}}$ & $10,30^{\mathrm{bA}}$ & $4,46^{\mathrm{aB}}$ \\
\hline & 11 & $4,54^{\mathrm{aB}}$ & $12,66^{\mathrm{aA}}$ & $5,54^{\mathrm{aB}}$ \\
\hline \multirow{3}{*}{$\mathrm{DR}(\mathrm{mm})$} & 5 & $0,037^{\mathrm{aB}}$ & $0,035^{\mathrm{bB}}$ & $0,067^{\mathrm{aA}}$ \\
\hline & 8 & $0,053^{\mathrm{aB}}$ & $0,042^{\mathrm{bB}}$ & $0,058^{\mathrm{bA}}$ \\
\hline & 11 & $0,035^{\mathrm{aC}}$ & $0,056^{\mathrm{aB}}$ & $0,063^{\mathrm{bA}}$ \\
\hline \multirow{3}{*}{$\operatorname{MSSR}(\mathrm{g})$} & 5 & $0,049^{\mathrm{aA}}$ & $0,065^{\mathrm{bA}}$ & $0,011^{\mathrm{aB}}$ \\
\hline & 8 & $0,048^{\mathrm{aB}}$ & $0,090^{\mathrm{aA}}$ & $0,017^{\mathrm{aC}}$ \\
\hline & 11 & $0,039^{\mathrm{aB}}$ & $0,100^{\mathrm{aA}}$ & $0,018^{\mathrm{cB}}$ \\
\hline \multirow{3}{*}{ PA/SR $\left(\mathrm{g} \mathrm{g}^{-1}\right)$} & 5 & $10,41^{\mathrm{bA}}$ & $7,38^{\mathrm{bB}}$ & $9,09^{\mathrm{bB}}$ \\
\hline & 8 & $10,63^{\mathrm{bB}}$ & $10,53^{\mathrm{aB}}$ & $23,53^{\mathrm{aA}}$ \\
\hline & 11 & $18,21^{\mathrm{aB}}$ & $10,50^{\mathrm{aC}}$ & $23,33^{\mathrm{aA}}$ \\
\hline
\end{tabular}

Diferenças estatísticas entre médias obtidas entre tamanho de estaca são indicadas por diferentes letras minúsculas. Diferentes letras maiúsculas representam diferenças estatísticas entre médias nos diferentes substratos (Tukey, $\mathrm{p} \leq 0,05$ ).

razão das mudas produzidas com estacas de $5 \mathrm{~cm}$ apresentarem menor taxa de replante.

\section{CONCLUSÃO}

A propagação vegetativa do tomateiro é viável, contudo maiores estudos sobre substratos alternativos, condições de enraizamento e padrão do material vegetal utilizado devem ser realizados.
CHENG, S.S.; CHU, E.Y. 2004. Técnica de Enraizamento de Ponteira para Propagação e Cultivo do Tomateiro. Comunicado técnico. ISSN 1517-2244 Dezembro, Belém, PA.

FACHINELLO, J.C.; HOFFMANN, A.; NACHTIGAL, J.C.; KERSTEN, E.; FORTES, G.R.L. 1995. Propagação 
de plantas frutíferas de clima temperado. 2.ed. Pelotas: UFPel, $178 \mathrm{p}$.

FERNANDES, A.A.; MARTINEZ, H.E.P.; SILVA, DERLY, J.H.; BARBOSA, J.G. 2004. Produção de mudas de tomateiro por meio de estacas enraizadas em hidroponia. Pesquisa Agropecuária Brasileira, Brasília, v. 39, n. $\approx 4$, p. 343-348.

FOSTER, G.S. 1993. Selection and breeding for extreme genotypes. In: AHUJA, M.R.; LIBBY, W.J. (Ed.). Clonal forestry - I: genetics and biotechnology. Berlin: Springer, p. 50-67.

GÛL, A.; TUZEL, Y.; YOLTAS, T. 1994. Possibilities of using side shoots as propagation material in greenhouse tomato production. Acta Horticulturae, n. 366, p. 271-278.

HARTMANN, H.T.; KESTER, D.E. 1990. Propagación de plantas: principios y practicas. 4.ed. México: Continental, $760 \mathrm{p}$.

LAMAIRE, F. 1995. Physical, chemical and biological properties of growing medium. Acta Horticulturae, v. 396, p. 273-284.

LUZ, J.M.Q.; PAULA, E.C.; GUIMARÃES, T.G. 2000. Produção de mudas de alface, tomateiro e couve-flor em diferentes substratos comerciais. Horticultura Brasileira, v. 18 , suplemento, p. 579-581.

MINAMI, K. 1995. Fisiologia da produção de mudas. São Paulo: T.A. Queiroz, 129 p.

PAIVA, H.N.; GOMES, J.M. 1995. Propagação vegetativa de espécies florestais. Viçosa: UFV, 40 p.

PRAGANA, R.B. 1998. Potencial do resíduo da extração da fibra de coco como substrato na produção agrícola. Recife: UFRPE, 84 p. (Tese mestrado).

RIZZO, A.N.; BRAZ, L.T. 2002. Enraizamento de brotos laterais de tomate tipo cereja em diferentes substratos. Campinas: IAC, p. 106 (Documentos).

SILVEIRA, E.B.; RODRIGUES, V.J.L.B.; GOMES, A.M.A.; MARIANO, R.L.R; MESQUITA, J.C.P. 2002. Pó de coco como substrato para produção de mudas de tomateiro. Horticultura Brasileira, Brasília, v. 20, n. 2, p. 211-216.

SMIDERLE, O.J.; SALIBE, A.B.; HAYASHI, A.H.; MINAMI,

K. 2001. Produção de mudas de alface, pepino e pimentão em substratos combinando areia, solo e plantmax. Horticultura Brasileira, Brasília, v. 19, n. 3, p. 253-257. 